\title{
Some doctors unsure how to handle undocumented patients
}

\author{
n Cite as: CMAJ 2019 November 18;191:E1285-6. doi: 10.1503/cmaj.1095803
}

Posted on cmajnews.com on October 30, 2019

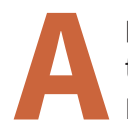
patient with uncertain immigration status comes to you for care. Do you know what to do? Are you aware of your legal duties? What about your ethical duties?

It's uncertain how many undocumented immigrants live in Canada but more than 45000 filed for refugee claims between 2017 and 2019. Health workers often don't know what to do when seeing patients who lack documentation, and policies in medical institutions can make the situation of these patients more precarious, experts say.

"Sometimes health care providers feel nervous around providing care to people who do not have immigration status, because they're not sure if there's some sort of legal duty to report," says Dr. Ritika Goel, a family physician at St. Michael's Hospital in Toronto. In fact, there is no such duty, she says. "Reporting somebody would be a violation of their confidentiality and against professional ethics."

Anecdotally, some doctors who care for undocumented immigrants say the situation can be further complicated by payment issues. Walk-in clinics and hospitals may charge upfront if patients don't have provincial health insurance, and in some cases, may turn away those who can't afford to pay.

Health workers shouldn't reject patients without first assessing the potential severity of their problems, says Dr. Paul Caulford, a family doctor who runs the
Canadian Centre for Refugee and Immigrant Health Care in Scarborough. "We regularly treat seriously ill patients turned away by walk-in clinics." Caulford recalls the case of a child with asthma needing a patients won't be billed or will face no consequences if they can't afford to pay. But even when a doctor declines to bill for their services, a hospital may still bill the patient and follow up with collection

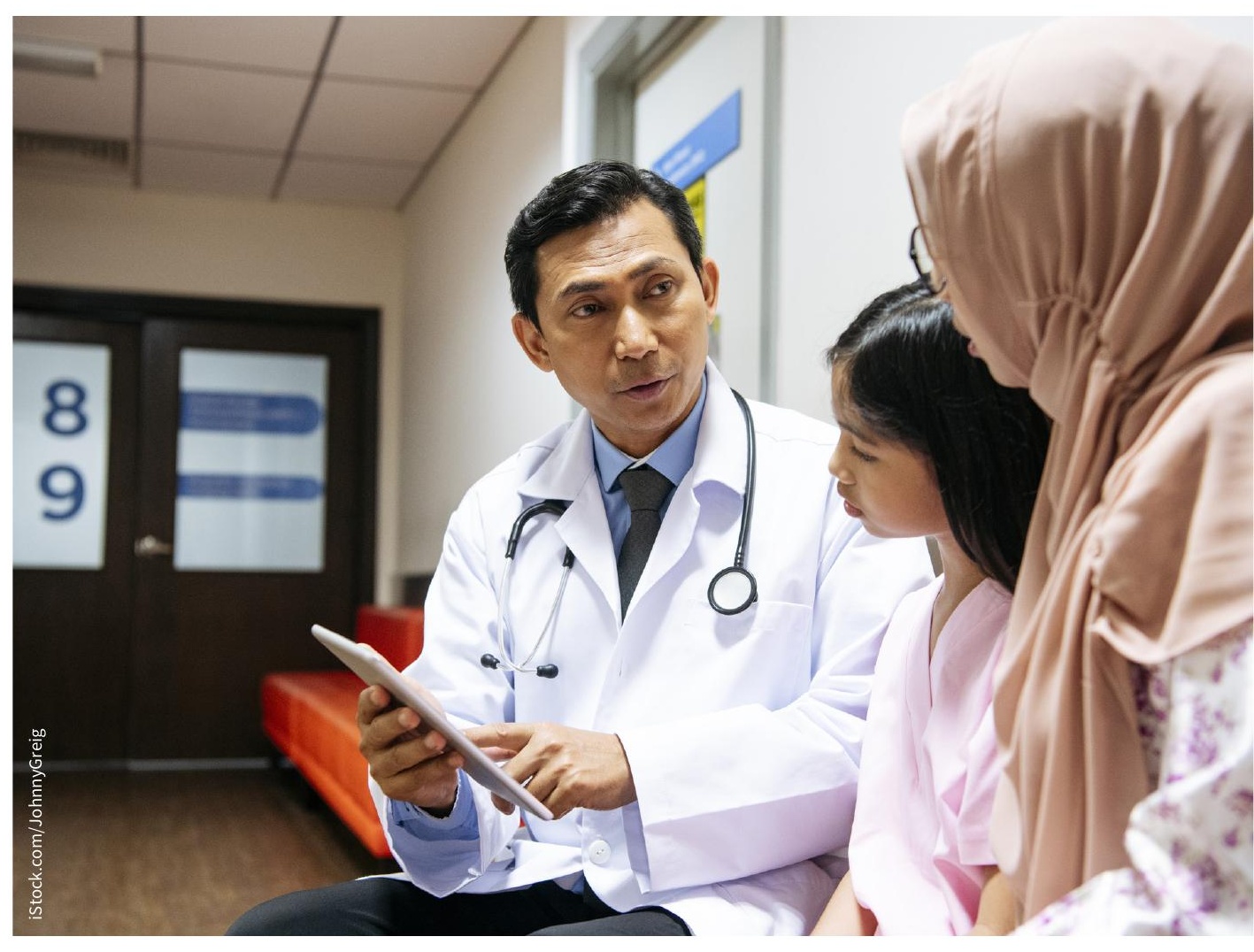

Undocumented immigrants face administrative and financial barriers to care that doctors may not realize. ventilator, oxygen and a nebulizer in hospital after being turned away by another clinic without assessment.

According to Goel, doctors who work in hospitals are often unaware of their own institution's policies and sometimes give patients inaccurate information. For instance, they may think that agencies. Goel questions whether some hospitals intentionally keep doctors in the dark about these policies to avoid pushback. "They may not want clinicians to know what happens on the finance end."

Hospital doctors who are aware of these internal policies spend a lot of time 
agonizing over how best to provide treatment, says Dr. Reed Siemieniuk, an internal medicine specialist at William Osler Health Centre in Etobicoke and Hamilton Health Sciences. "Any decisions we make about how far to go with investigations, we really need to put a lot of thought into it," he says. That includes discussing with the patient how important a test might be, what it might mean to forgo it, and what it will cost.

"Every time you want to order a diagnostic imaging test like a CT scan or MRI, the patient will have to pay upfront for that," says Siemieniuk (unless it's an emergency, in which case payment can be deferred). Upfront charges can sometimes be avoided with some advocacy, like a call to the radiology department, he notes. These situations happen "all the time, almost every day."

Doctors may also be unaware of programs that help uninsured patients. For instance, people who have been accepted as refugees are eligible for the Interim Federal Health Program, which provides similar coverage to provincial health insurance. All hospitals accept this coverage. Doctors outside of hospitals, however, are not required to participate in the program and some decline. At minimum, Caulford says, they should know and share the names of doctors in their area who do accept federal health coverage.

For people who have no health coverage at all, there are a few clinics (such as Caulford's) that offer primary care free of charge. He says all doctors should keep a list of free clinics and other community health resources to share with patients in need.

Above all, Caulford says, "don't judge." Many undocumented immigrants have suffered emotional, mental and physical trauma. "Educate your staff in terms of sensitivity, even if your clinic is unable to provide care."

Alison Motluk, Toronto, Ont. 